\title{
Giant pedunculated mixed mesenchymal tumor- hamartoma of the esophagus: A case report and literature review
}

\author{
Artur Zakoscielny, Witold Zgodzinski*, Pawel Bury, Norbert Nowak, Agnieszka Fronczek, Grzegorz Wallner and Krzysztof Zinkiewicz \\ $2^{\text {nd }}$ Department of General, Gastrointestinal Surgery and Surgical Oncology of the Alimentary Tract, Medical University of Lublin, Poland
}

\begin{abstract}
Pedunculated polyps of the esophagus containing elements of the mesenchymal tissue are benign tumors that occur in the cervical and upper thoracic esophagus, particularly in the region of the cricopharyngeus muscle. Large pedunculated tumors, can cause dysphagia, dyspnea, or sudden choking. Herein, we describe the case of a 70-year-old man initially diagnosed with a $21 \mathrm{~cm}$ giant pedunculated mixed mesenchymal tumor of the esophagus. Our case study demonstrates endoscopic evaluation and the successful surgical resection of the esophageal lesion.
\end{abstract}

\section{Introduction}

In the majority of cases, fibrovascular polyps are benign intraluminal esophageal lesions. They account for less than $1 \%$ of all benign esophageal tumors [1]. Tumor-like lesions originate from the submucosal layer of the cervical esophagus, especially in the region of the cricopharyngeus muscle. These lesions are typically observed in middle-aged and elderly men. Their symptoms correlate with the tumor size; however, patients report dysphagia, dyspnea, sense of "fullness" in the throat, or choking and their primary symptoms. Long pedunculated tumors may cause life-threatening complications such as regurgitation of the tumor and sudden death due to asphyxia [1]. In the literature, 10 cases of sudden death have been reported [2]. Herein, we present the case of a patient with a pedunculated esophageal tumor with increasing dysphagia, who was treated surgically by left side cervicotomy.

\section{Case report}

A 70-year-old man, who was treated for polycythemia vera, was admitted to our department due to increasing dysphagia to solid foods and odynophagia during the previous 4 years. In January 2013, hypopharyngoscopy was performed, but no pathological findings were noted. In January 2017, a computed tomography (CT) scan of the neck revealed a proximally enlarged esophagus with a compressed light in the distal part and several asymmetrically enlarged $13 \times 16 \mathrm{~mm}$ lymph nodes in the neck (Figure 1). CT scans of the chest revealed scattered emphysematous lesions in the upper parts of the lungs and several focal lesions in both the lobes of the lungs. The entire CT images raised suspicion of the delamination of the esophagus wall by the presence of airspace and fluid collation areas (Figures 2 and 3). Because of the lack of a clear diagnosis, a gastroscopic examination was performed. Endoscopic examination revealed a large polyp of the esophagus on a long and thick peduncle (about $20 \mathrm{~cm}$ ) with the head blocking the gastro-esophageal junction (GEJ) ((Figures 4 and 5). The patient's condition was discussed at the multidisciplinary meeting and because of the size of the tumor and its location, surgical resection was recommended. Surgical excision of the giant tumor was performed. A left cervicotomy was performed

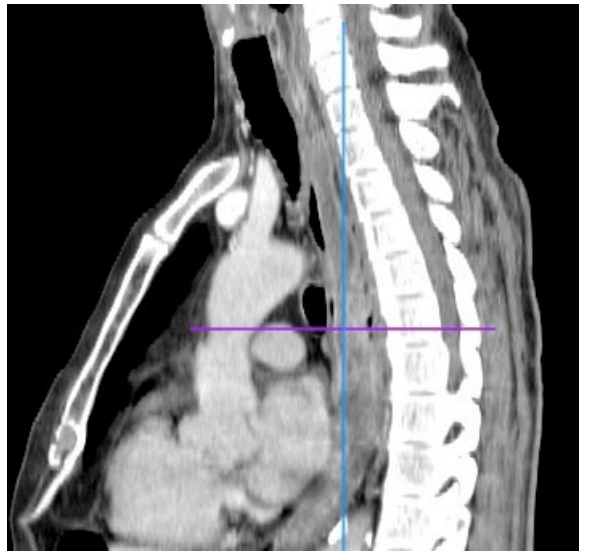

Figure 1. Computed tomography scan, proximal enlarged esophagus with a compressed lumen in the distal part

along the left sternocleidomastoid muscle. The cervical part of the esophagus was dissected and then opened. Myotomy was performed along the left-sided margin of the esophagus and then on a similar section of the mucosa. The hanging polyp was extruded with a pair of forceps, thus revealing the peduncle on the border of the posterior wall of the esophagus and the throat ((Figures 6 and 7). The tumor on the stem of the pedicle was then gradually excised (Figure 8 ). There was no evidence of invasion of the esophageal wall. The hemostatic suture was placed on the base. The mucosa was continuously sutured and was covered with the muscle layer. A nasogastric tube was placed.

${ }^{\star}$ Correspondence to: Witold Zgodzinski, $2^{\text {nd }}$ Department of General, Gastrointestinal Surgery and Surgical Oncology of the Alimentary Tract, Medical University of Lublin, Poland, Tel: +48 81 5328810, E-mail: hie-wzgodz@wp.pl

Key words: esophagus, pedunculated polyp, hamartoma

Received: July 02, 2020; Accepted: July 27, 2020; Published: July 31, 2020 


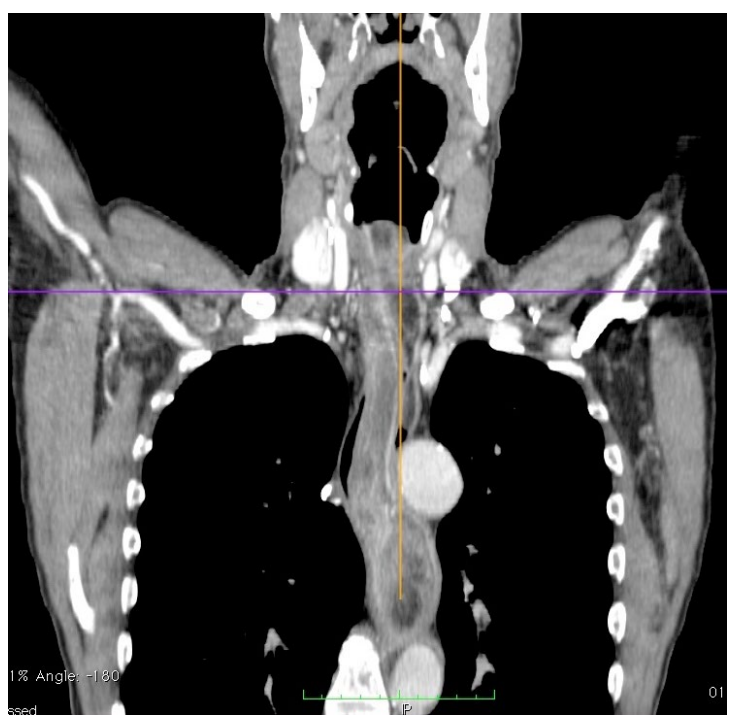

Figure 2. Computed tomography scan, delamination of the esophagus wall by the presence of air space and fluid collation areas

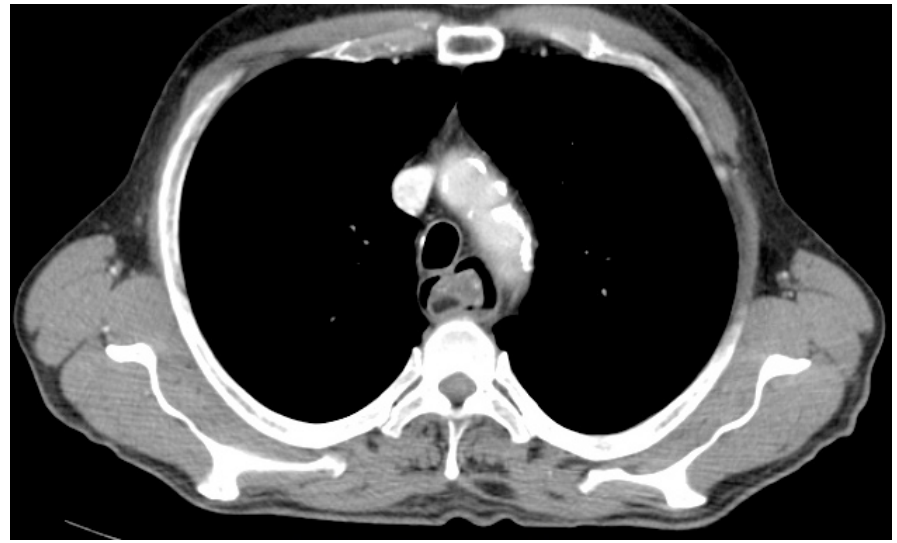

Figure 3. Computed tomography scan

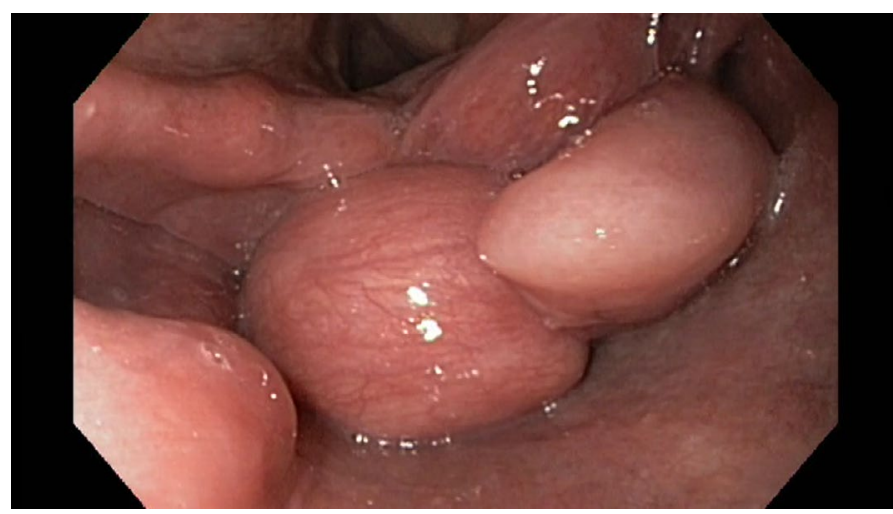

Figure 4. Endoscopic image - the base of the polyp stalk

Histological examination revealed a $21 \mathrm{~cm}$ mixed mesenchymal tumor - hamartoma, angiomyolipoma with spindle-cell lipoma, and atypical well-differentiated cells (CD34+, CD117-, SMA-, HMB45-, LPX:4). Histopathological examination revealed no malignancy (Figures 9-11). Postoperative course was uneventful. Water-soluble contrast roentgenoscopy was performed on the fifth postoperative day, which showed no signs of the fistula. The patient was discharged on the eighth day after the procedure.

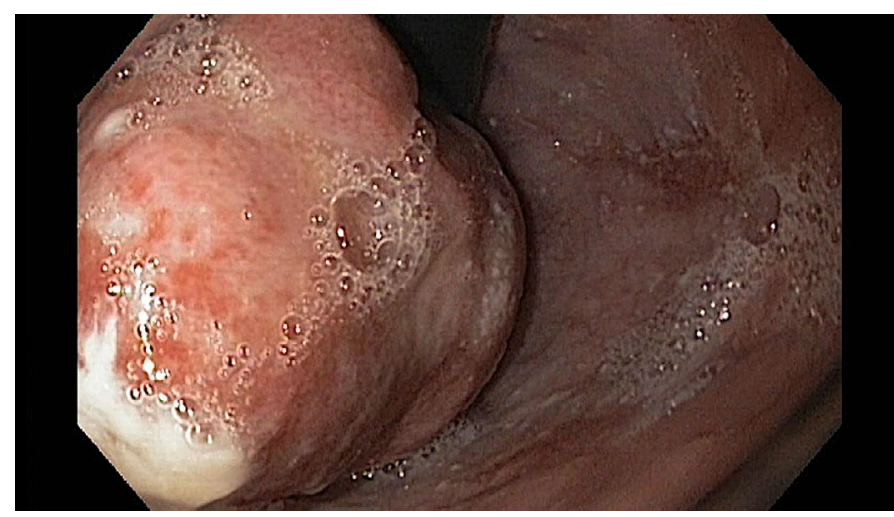

Figure 5. Endoscopic image - the polyp head blocking the esophago-gastric junction

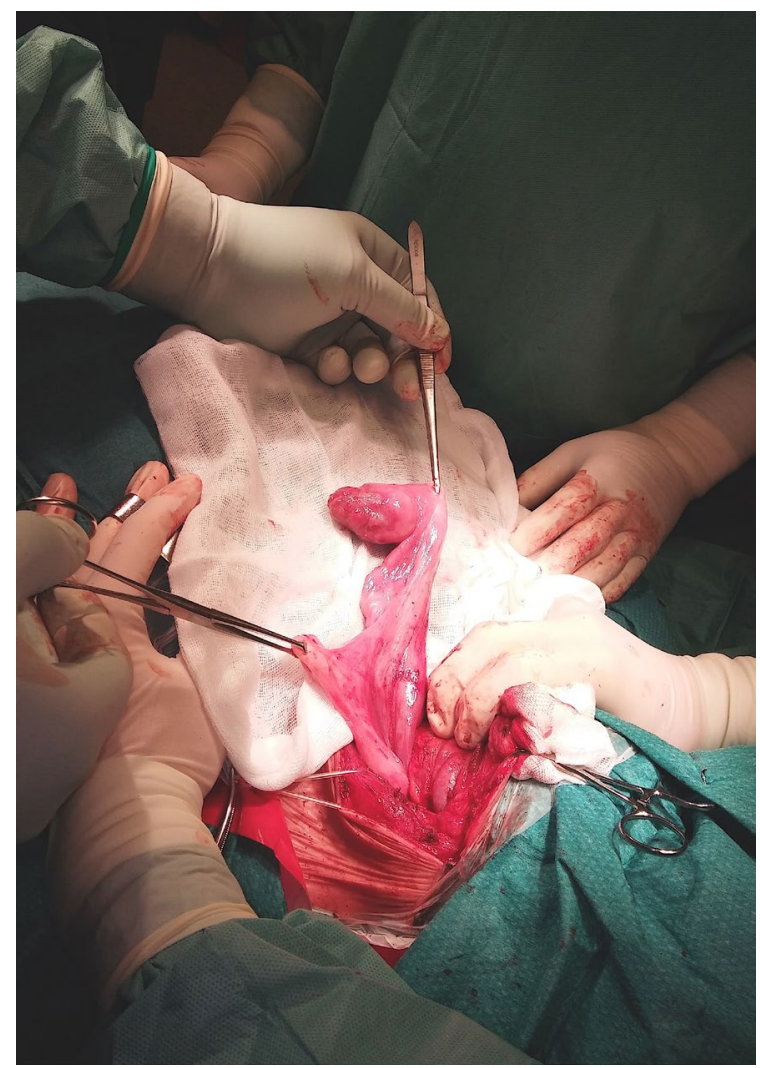

Figure 6. Surgical view, the tumor on the stem of the pedicle

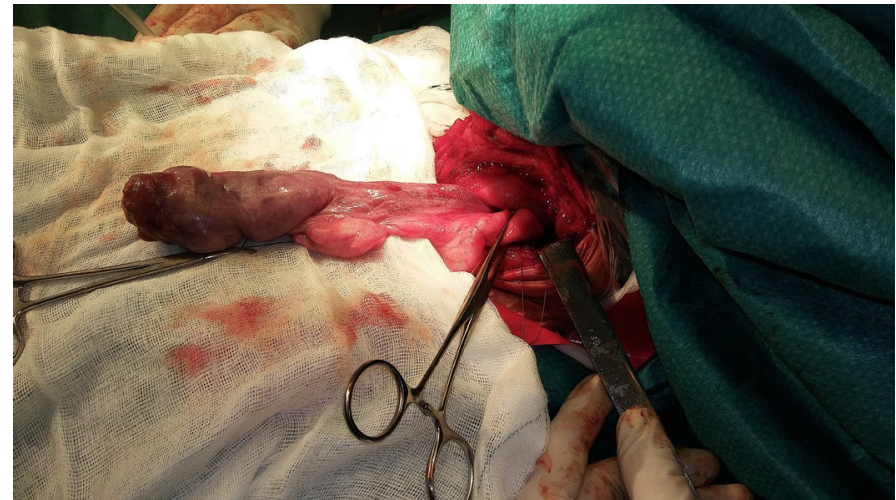

Figure 7. The tumor on the stem of the pedicle 


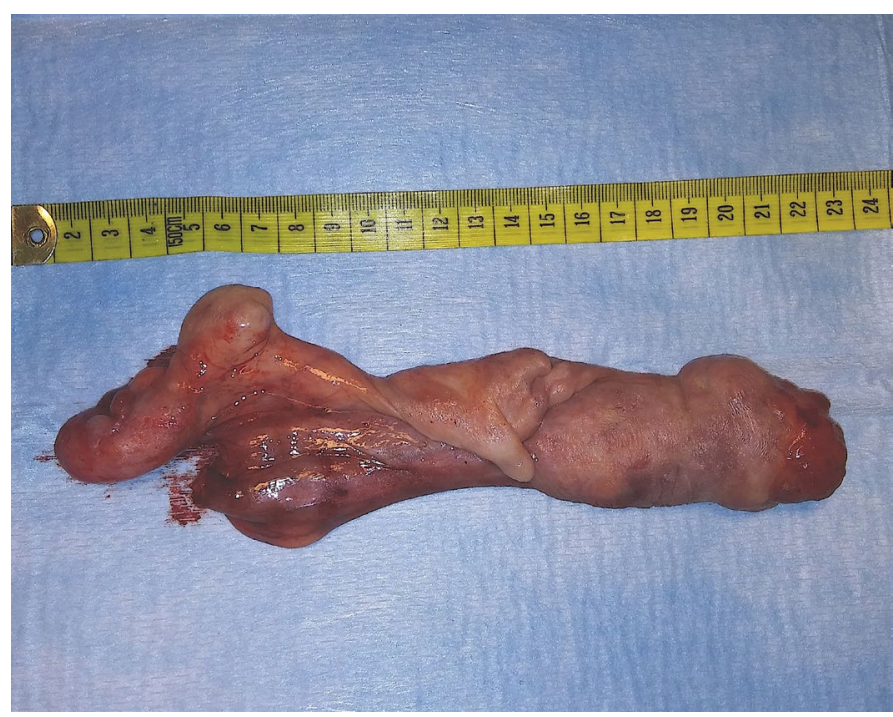

Figure 8. The specimen of the 21-cm giant pedunculated mixed mesenchymal tumor of the esophagus

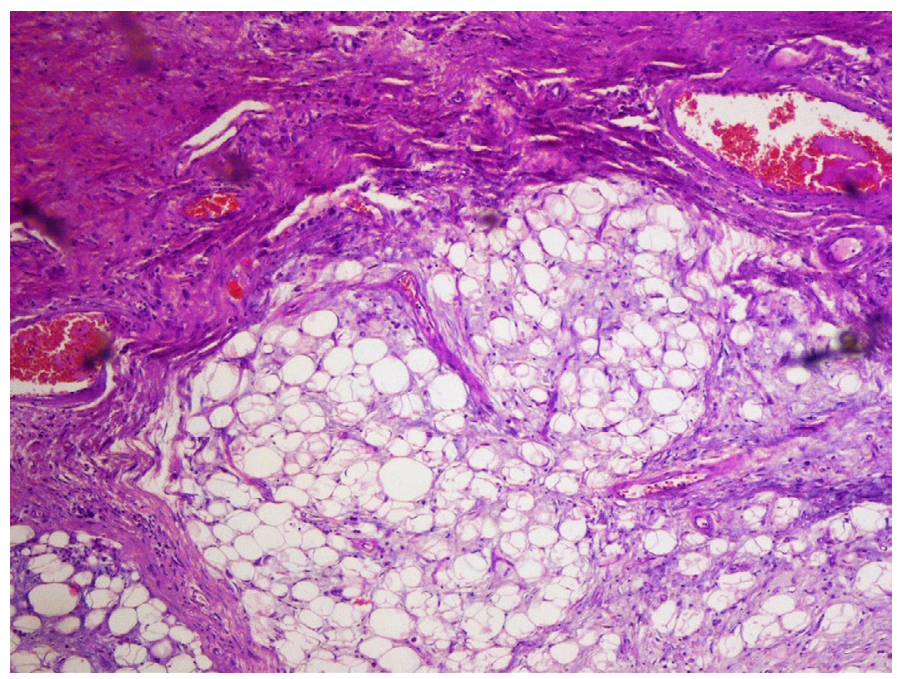

Figure 9. Microscopic image-the tumor composed of fibrous tissue, blood vessels and adipose tissue $(\mathrm{H}+\mathrm{E}$; magnification $5 \mathrm{x})$

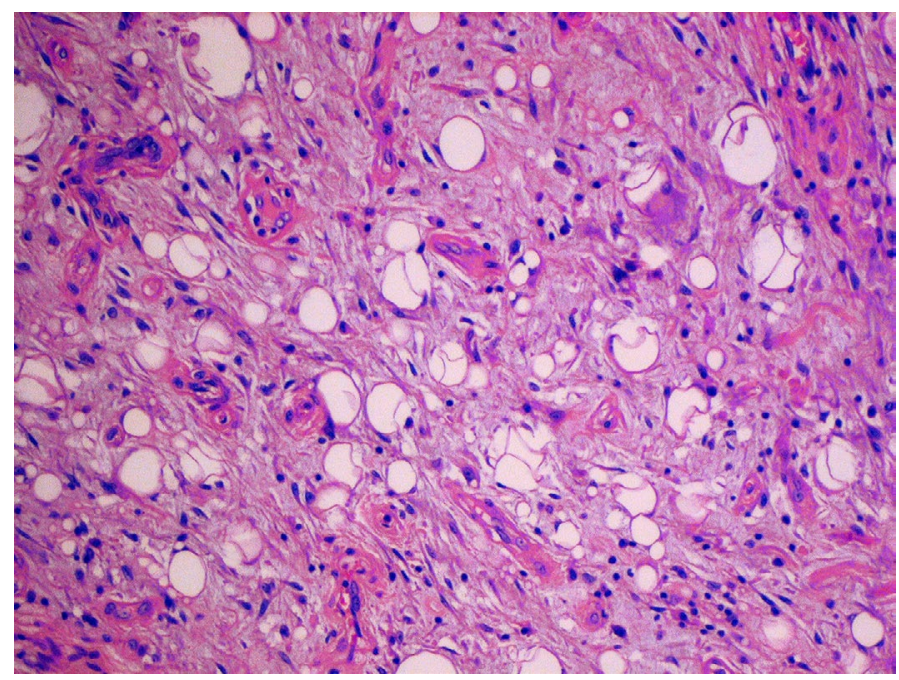

Figure 10. Microscopic image-the lesion contains component of spindle cell lipoma $(\mathrm{H}+\mathrm{E}$; magnification $10 \mathrm{x}$ )

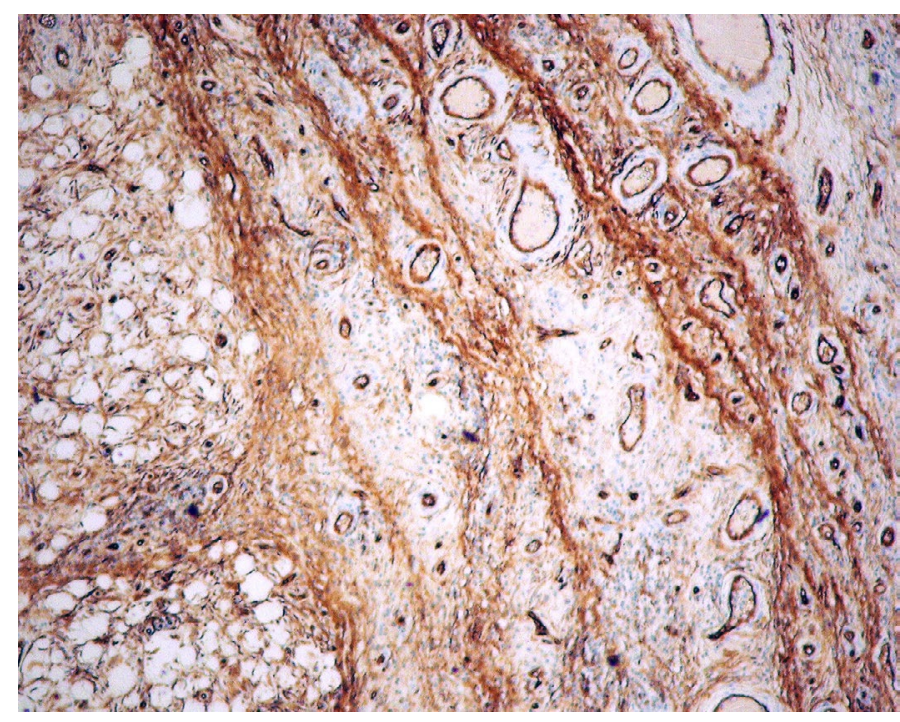

Figure 11. Microscopic image - immunohistochemical reaction for CD34 (magnification $5 \mathrm{x})$

\section{Discussion}

Our case study demonstrates endoscopic evaluation and the successful surgical treatment of the giant pedunculated mixed mesenchymal tumor - hamartoma of the esophagus. Described lesion was extremely large, arising from hypopharynx and reaching gastric cardia. In CT scans the image of "double lumen" esophagus was described suggesting certain type of congenital pathology. Initial endoscopic assessment was also not conclusive due to unusual image of huge tumor covered with unchanged mucosa, that filled almost entire esophageal lumen. Such large tumors are extremely rare [3]. The exact etiology of this pathological tumor is not well known. Most of these polyps are benign and remain asymptomatic for many years. The most common symptoms in these cases are regurgitation of a mass $(61 \%)$, dysphagia (54\%), dyspnea (33\%), vomiting (31\%), laryngeal discomfort (23\%), weight loss (15\%), and syncope (8\%) [3]. Extremely large polyps can cause potentially life-threatening conditions and therefore should be removed immediately. Different approaches can be applied to treat this condition: surgical approaches (cervicotomy and thoracotomy) or transoral approaches (endoscopy and laryngoscopy). The choice of the method depends on the tumor location, pedicle vascularity, and tumor size. In the majority of cases, surgical resection is the primary method of treatment $[4,5]$. It improves better control of bleeding, especially in thick pedicule. Preoperative diagnosis and location of the base of the pedicle is crucial for surgical strategy. These kinds of lesions are generally benign, and esophagectomy is not required. Endoscopic removal of the fibrovascular tumors is an alternative technique [6] but it is recommended for small lesions that are less than $2 \mathrm{~cm}$ in diameter with thin pedicles. Polyps/tumors larger than $8 \mathrm{~cm}$ in length or those with thick, richly vascularized pedicles should be removed by surgical excision $[7,8]$.

\section{Conclusion}

In conclusion, esophageal mixed mesenchymal tumors are benign intraluminal neoplasms that rarely occur in the upper gastrointestinal tract. Giant pedunculated tumors may cause many diagnostic controversies. They should be removed by means of surgery or endoscopy. Surgical resection (cervicotomy) should be reserved for large tumors after pre-surgical localization of the base of the pedicle. 


\section{References}

1. Sestini S, Gisabella M, Pastorino U, Bille A (2016) Presenting symptoms of giant fibrovascular polyp of the oesophagus: case report and literature review. Ann $R$ Coll Surg Engl 98: e71-e73. [Crossref]

2. Carrisk C, Collins KA, Lee CJ, Prahlow JA, Barnard JJ (2005) Sudden death due to asphyxia by esophageal polyp. Am J Forensic Med Pathol 26: 275-281. [Crossref]

3. Oka M, Ueha R, Nito T, Yamasoba T (2016) Giant fibrovascular polyp in the hypopharynx: a case report and review of the literature. Springerplus 5: 1443. [Crossref]

4. Jin-Seok P, Byoung Took B, Junyoung S, Kwon KS, Kim HG, et al. (2014) A case of esophageal fibrovascular polyp that inducted asphyxia during sleep. Clin Endosc 47: 101-103. [Crossref]
5. Jie L, Hua Y, Renfu P, Lu Z (2016) Gastroscopic removal of a giant fibrovascular polyp from the esophagus. Thoracic Cancer 7: 363-366. [Crossref]

6. Valiuddin HM, Barbetta A, Mungo B, Montgomery EA, Molena D (2016) Esophageal liposarcoma: well-differentiated rhabdomyomatous type. World J Gastrointest Oncol 8: 835-839. [Crossref]

7. Kim JS, Shim YM (2006) Giant brovascular polyp of the hypopharynx: surgical treatment with the biappoach. J Korean Med Sci 21: 749-751. [Crossref]

8. Wang J, Han DM, Ni X, Li-jing MA, Jing-ying YE, et al. (2011) Fibrovascular polyp of the hypopharynx and esophagus. Chin Med J (Engl) 124: 3182-3184.

Copyright: $\bigcirc 2020$ Zakoscielny A. This is an open-access article distributed under the terms of the Creative Commons Attribution License, which permits unrestricted use, distribution, and reproduction in any medium, provided the original author and source are credited. 